\title{
DIFFERENT APPROACHES TO DESING OF THE GROUP TRANING IN ADULT LEARNING
}

\author{
SOFIIA HRABOVSKA \\ Ivan Franko National University of Lviv \\ Faculty of Philosophy, Department of Psychology \\ Universytetska Street 1, Lviv, Ukraine \\ E-mail address: sofiia.hrabovska@lnu.edu.ua \\ ORCID number: https://orcid.org/0000-0003-4256-1191 \\ NATALIIA HREBIN \\ Ivan Franko National University of Lviv \\ Faculty of Philosophy, Department of Psychology \\ Universytetska Street 1, Lviv, Ukraine \\ E-mail address : nataliya.hrebin@Inu.edu.ua \\ ORCID number: https://orcid.org/0000-0002-9473-0404 \\ RUSLANA KARKOVSKA \\ Ivan Franko National University of Lviv \\ Faculty of Philosophy, Department of Psychology \\ Universytetska Street 1, Lviv, Ukraine \\ E-mail address: ruslana.karkovska@lnu.edu.ua \\ ORCID number: https://orcid.org/0000-0003-0416-4371
}

\begin{abstract}
Aim. The aim of the study is a description of the types of training designs, based on various classification criteria and illustrated by examples from the authors' own practice.

Methods. We used theoretical analysis and synthesis of scientific information, as well as modelling the training structure.

Results and Conclusions. It was proposed to classify the designs of group training, depending either on the internal logic of the teaching material or on the external organisation of the training. Regarding the logic of presentation certain designs, through the analysis of existing learning approaches, are proposed of training, based on different logic: presentation of information, assimilation of information, B. Bloom's taxonomy, and competencies formation. Using these designs, it is possible to construct either the whole training or
\end{abstract}

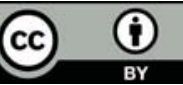


its separate parts (thematic blocks, exercises). The external organisation of the training includes design of the sum of exercises, or of a coherent story.

Key words: adult teaching, life long education, training technologies, training design.

\section{INTRODUCTION}

$\mathrm{T}$ he importance of adult teaching is growing worldwide. This is due to modern trends in the labour market, caused by scientific and technological progress, and by innovative processes in various spheres of human life. The demographic composition of labour resources is constantly changing, leading to the intensification of competition for vacancies. Now the employee is expected to master a much larger amount of knowledge, skills and abilities, than in the recent past. Accordingly, the main goal of adult teaching is growth of professionalism, motivation for oneself's continuous improvement as a specialist, as well as disclosing the potential for personal growth and self-actualisation.

The research results show numerous benefits of continuing education in adulthood, not only for the professional sphere, but also for the personal motives. Leon Feinstein and Cathie Hammond reveal that learning promotes the personal and social development of adults, reduces the risks of stagnation and psychological distress, increases trust in others, and raises social awareness (Feinstein \& Hammond, 2004, pp. 216-217). Adults, involved in a variety of training programmes, feel healthier and more satisfied; they tend to lead a healthy lifestyle, build new social relationships more successfully, are more motivated to participate in lifelong learning, and consider it an opportunity to improve their lives (Manifesto for Adult Learning in the 21st Century EAEA, 2019). That is why the development and implementation of effective technologies for adult learning makes a great scientific interest and an urgent task of science and practice. The development and implementation of learning technologies becomes a strategic vector for the establishment of adult education as a holistic system of lifelong learning (Vovk, 2019, p. 41).

Adult learning has certain specific traits. After Malcolm Knowles, in adult learning the following phenomena must be taken into account: the adult students' needs in knowledge, their self-awareness, past experience, willingness to learn, attitude, and learning motivation (Knowles, Nolton \& Swanson, 2005, pp. 61-63). The desire to learn among adults arises when they realise the importance of knowledge to achieve their life goals. During training, it is advisable to rely on the already existing student individual experience, in order to establish links between the acquired and current knowledge. Adults are much more independent, they have an intrinsic motivation, which can be enhanced by properly organised learning. It should be noted that adult learning is most effective when the students have an opportunity to train their skills, apply the new knowledge in practical tasks, simultaniously gaining confidence in their 
ability to solve professional or other actual problems. Accordingly, the effectiveness of adult learning increases with the use of active teaching methods, which help the students' experience and knowledge become a source of mutual learning and mutual enrichment of the educational process (Lukyanova, 2013, pp. 7-8). Training technologies (including active teaching methods) are increasingly used in adult education in order to practice various skills, to improve professional knowledge, the development of emotional and volitional sphere, interpersonal interaction, and more. This study is aimed to describe the ways of training design on the basis of various classification criteria, illustrated by practical examples.

\section{THEORETICAL FRAMEWORK}

Adults usually prefer to learn without much effort, and to develop their skills and abilities in the process of interactive training. Group training is a form of organisation of educational activities, which provides active communication on the basis of constant interaction of all its participants; it involves the formation or development of competencies, using the previous experience of the students and their constant reflection (Miroshnyk, 2012). Polina Bavina noted that training technologies should be considered in the context of activity learning, because they are based on the basic principles of game modeling and are balanced by traditional and non-traditional simulation teaching methods (Bavina, 2004, pp. 9-10). Working on the construction of training, the trainer should formulate its concept, purpose and objectives, develop a programme of the training (with justification of its division into thematic modules), its design, methodological support, working materials, and the methods of results evaluation (Anishchenko, 2015, p.15).

The training design and the compliance of its tasks with the problems that the adults are facing in their everyday life (particularly at work) significantly affect the motivation of the training participants (Mount \& Mazerolle, 2020). Learning objectives, scope and specifics of the participants prompt the formation of various strategies and methods of training. Eduardo Salas and Janis A. Cannon-Bowers made a research review dedicated to the training process. They identified several types of group training: team training, collaborative training, role modeling training, and stress training. Team training aims to develop guidelines and skills to improve the efficiency of teamwork. In collaborative training, unlike team training, group tasks are not required, but group interaction is one of the learning tools. Role modeling allows you to practice behavioural skills in situations close to real, and stress training is aimed at preparing participants for work in stressful conditions through working with guidelines for stress and development of behavioural skills in stressful conditions (Salas \& Cannon-Bowers, 2001).

Emotions play a significant role in adult learning. These may be either reactions to the learning environment or feelings related to personal experiences. In 
the learning environment, adults often react emotionally to differences and disputes between participants, to the way the learning is organised, to proposed tasks, and to expected assessment. Emotions can create learning barriers, but they can also make a resource for learning improvement (Dirkx, 2008).

The training design may differ in the following parameters:

- the clarity of the instructions received by the participants (exploratory learning, guided exploration);

- the framework that forms the focus on the task (error framing, practice framing);

- the focus of the coach's interventions to help participants work with emotions (emotion-control statements, guided practice).

Empirical results show that guided exploration leads to better results immediately after training, and exploratory learning - to a higher level of analogical transfer and adaptive transfer performance. Emotion-control strategy negatively correlates with anxiety, avoidance orientation, and self-assessment of participants, and positively - with self-effectiveness, state mastery orientation and state proven orientation. Error framing is positively correlated with adaptive transfer (Bell \& Kozlowski, 2008).

The classification of group training designs can be based on the logic of either the material presentation or the external organisation of training. If the classification is based on the logic of the presentation of educational material, then we can separate the following types of training scenario:

- According to the logic of presenting the information: deductive, inductive, by analogy (Kovaleva, 2005);

- According to the logic of information assimilation: "see and hear $\rightarrow$ discuss $\rightarrow$ experience $\rightarrow$ explain to others" (O'Connell, Medeni, 2014; Duran, 2017);

- According to the logic of B. Bloom's taxonomy: assimilate $\rightarrow$ understand $\rightarrow$ apply $\rightarrow$ analyse $\rightarrow$ create $\rightarrow$ evaluate (Bloom, 1984; Anderson \& Krathwohl, 2001);

- According to the logic of competence formation: unconscious incompetence $\rightarrow$ conscious incompetence $\rightarrow$ conscious competence $\rightarrow$ unconscious competence (Broadwell, 1969; Geller, 2002).

The training construction based on the logic of the information presentation provides taking into account the purpose of training, the content of a particular topic, the preparedness of the participants. Sometimes the same topic can be presented in different ways, and it does not require a strictly determined training design. In such cases the design may depend on the individual preferences of the coach, and may be based on the principles of deductive or inductive logic of presentation, or on the principle of differently aimed analogies. Of course, you can combine these methods, especially if the training is long, not limited to one short session. It is clear that the choice of the training construction type depends on its purpose, topic, and features of the audience. 
Deductive construction requires starting with a mini-lecture, where the trainer should set out the general provisions, patterns, mechanisms of what should be learned, and then you can use exercises to analyse cases where these patterns are included in specific practical activities.

Inductive construction of the training scenario consists of reverse actions: it begins with introductory exercises (illustrative, situational, role play, or any other activities that allow revelation of a specific manifestation of the studied phenomenon); then, in the process of further discussion of the results, participants formulate general patterns and mechanisms; and after that, the coach summarises the results. The exploratory learning is based on an inductive approach, providing the conditions that encourage people with higher cognitive abilities to work more actively (Bell \& Kozlowski, 2008).

The analogy-based training design allows you to go from a partial (single) example to a partial (single) conclusion. In order to solve a certain problem, the trainer can decide to work on situational exercises in accordance with the problems of the training. Working with those problems, training participants can find out some interesting algorithms for solving certain types of problems, and come across the effective solutions. You can also successfully use synectic brainstorming. Here the general rules of brainstorming remain unchanged: free expression of ideas; stimulating the originality of ideas, exchanging views, encouragement of associations; prohibition of criticising the expressed ideas; stimulating more ideas. Shi Cheng and colleagues identified two types of brainstorming functionality, capability learning and capacity developing: "the capacity developing focuses on moving the algorithm's search to the area(s) where higher potential solutions may exist, while the capability learning focuses on its actual search towards a new solution from the current solution for the single-point based optimisation algorithms and from the current population of solutions for population-based swarm intelligence algorithms" (Cheng et al., 2017, 1637).

Practical experience in the development and implementation of training in adult learning shows that participants of different ages, specialties and education are usually willing to work with different types of analogies (table 1)

Table 1.

Table of analogies used in the training process

\begin{tabular}{ll}
\hline \multicolumn{1}{c}{ Analogy } & \multicolumn{1}{c}{ Meaning } \\
\hline direct analogy & $\begin{array}{l}\text { participants recall examples of solved problems from their } \\
\text { own experience; it is worth remembering the successful and } \\
\text { unsuccessful actions }\end{array}$ \\
\hline personal analogy & $\begin{array}{l}\text { participants need to put themselves on the place of the problem } \\
\text { subject and to reason from own point of view }\end{array}$ \\
\hline symbolic analogy & $\begin{array}{l}\text { participants try to provide a metaphorical definition of the } \\
\text { essence of the problem }\end{array}$ \\
\hline fantastic analogy & $\begin{array}{l}\text { participants try to imagine how this task would be solved by } \\
\text { fairy-tale or mythical characters, fantastic creatures, etc }\end{array}$ \\
\hline
\end{tabular}

Source: own research. 
The work with analogies can be organised in different ways: the whole group can work together on all analogies in turn; or it is possible to divide training participants into subgroups, to offer each group (or, for a small number of participants, each student personally) to work on a certain type of analogy. The obtained analogies are analysed, "translated" into the "language" of the problem. Then the ideas are generalised, criticised, tested for "strength", students formulate arguments "pro" and "contra", vote, and so on. It should be noted that deduction, as a type of logical presenting of the material or proof, is preferred by people with higher impulsivity level. But the coach should focus not only on their own taste, but also take into account the capabilities and preferences of students. Therefore, if the training is long (not limited to one session), it is necessary to change the presentation format, and to apply all kinds of logical constructions (deduction, induction, and analogy).

The approach to assimilating information by explaining it to others, according to the scheme: "see and hear $\rightarrow$ discuss $\rightarrow$ experience $\rightarrow$ explain to others", is based on research by Shannon O'Connell and AbdulSalam Medeni. According to this research, people remembered $10 \%$ from what they've read, $20 \%$ from what they've heard, 30\% from what they've seen, $40 \%$ from what they both saw and heard, $50 \%$ from what they discussed with others, and $70 \%$ from what they get through (felt, learned from experience) personally ( $\mathrm{O}^{\prime}$ Connell \&Medeni, 2014, p.31). An important element of personal experience is attempting to explain it to others.

According to David Duran, the experience of teaching someone the studied material has significant advantages over self-study. These processes involve different mental operations; in particular, preparing for teaching others encourages organisation and to structure the material. Duran cited numerous examples of research, including Robert Zajonc (1966), Carl Benware, Edward Deci (1984), Linda Annis (1983), Logan Fiorella and Richard Mayer (2013), and shows that students who studied the material and were willing to explain it to their colleagues, have mastered the knowledge more effectively. Explaining to oneself also promotes cognitive activity; however, explaining to others is a more powerful mechanism of learning, because the audience to whom the material is explained can find gaps in the teacher's knowledge, and they may also have a different point of view on the same facts - all this encourages deeper information. The results of the Duran's study show that the students who studied in groups mastered the knowledge better than the ones who used any other form of learning, and the least effective way of learning seems to be the one-way teaching. Thus, successful learning requires two-way interaction, in which there is an exchange of issues, information, and experience (Duran, 2017, p.5).

Therefore, the organisation of the training will be more effective if students have the opportunity to discuss, to experience the content of the exercises personally, and to explain, prove or teach the training material to someone. In fact, various methods of interactive learning are most effectively adapted for this purpose. For example, the Jigsaw technique (Aronson et al., 1978; Slavin, 
1980), which can be used for helping students to assimilate quite voluminous and complicated texts.

Prepare the text (about 4-5 pages) and divide it into 3-5 fragments: the number of the fragments should be equal to the quantity of groups. Every group should include an equal quantity of students. It may be very convenient to organise the groups using coloured cards. For this purpose, prepare some paper cards of different colours or with different pictures (one card for each group of students), and cut them into fragments in quantity equal to the number of students within the group.

On the back of each fragment write a sequence number (1, 2, 3...). Each student gets such a fragment of a certain colour and a number. Ask the students to unite in groups according to the numbers written on their fragment (for example, all 3rds). Give a text fragment to each group, but be sure that the group number and the sequence number of the text do not coincide, so that the parts of the text mix. The text fragments must not include the text title or the page number. The students should discuss their part of text in small groups, highlight its subject, analyse the structure and present the resulting piece of text visually (in the form of a diagram, drawing, etc.). The speaker of each group hangs out the designed poster and explains what is drawn, telling it close to the text but not reading it. The order in which the fragments are presented can be arbitrary, for example, arranged according to the group numbers (but it is desirable that the text fragments are not presented in a logical order). After presenting all the pieces of text, the students should discuss and establish the true sequence of the text, and hang posters of the text fragments in the proper order, so they reflect the logical sequence of the material.

The next step begins with formation of new groups, each including students that hold fragments of the same card. So, in that new group, every member is an expert on a particular piece of text. In the order of the established sequence of text fragments, each participant should give the content of his text fragment to his colleagues in a small group, so that all participants get to know the whole text perfectly. For the final mastering of the text, it is advisable to make a general knowledge test on the material. Such a test can be organised in different ways. For example, students can form a circle, and each gives one sentence in turn, until the text is fully told. It can be announced that the one who translates the whole text as accurately as possible will receive a prize, and the jury of the competition will be formed among other participants of the training. The coach should be creative and invent many different interesting options. In this exercise, students do not memorise the text mechanically, but actively work with it: listen, visualise, discuss with others and teach others. Practice shows the high effectiveness of such training.

The construction of the training or its components, based on the logic of B. Bloom's taxonomy, can be the following. Firstly, the coach offers some information that students should assimilate. That information can be submitted in a form of a mini-lecture, worked on with the method described above, or dis- 
cussed in the whole group (to update the information that each participant knows, and make it available for all students).

The next step is "understanding". The coach should ask the participants to provide examples that illustrate the acquired knowledge, to apply tasks, and to organise the obtained information in the form of diagrams, drawings, models, etc. A feedback technique may also give good results. This technique represents a system of questions, which the participants should ask, based on the new information. These options can be implemented individually by each participant, or in small groups of different numbers of students.

The "apply" stage can be organised by developing practical recommendations, and identifying areas of practical application of certain knowledge. After that, it is logical to analyse the developed proposals and recommendations, check them by identifying the balance of possible positive and negative consequences of these projects, etc.

The "create" stage can be organised in the following way. A large group should be divided into small ones (each including 3-5 students), and each group has to create some kind of a product (real object, narrative, imaginary object, idea, etc.). Each group demonstrates the results of their work, which are evaluated on a certain scale by colleagues from other groups. Next, organise a discussion to analyse the best aspects of all projects. It can be a good experience for participants to share these projects, and to try to describe how they can be realis This will help the students to understand the essence of the material and to learn it. It should be taken into account that one of the specific traits of the adult learning is the heterogeneity of the training group. The coach's aim is to show the students pros and cons of different experiences, and in particular, the very opportunity to look deeper into the problem from different positions, points of view, and so on.

When designing a training aimed at the formation of competencies, the first stage should be identifying the participants' "unconscious incompetence". For this purpose, students are asked to perform a task for which they certainly have not enough knowledge, skills, and abilities. To create the impression of "conscious incompetence", participants can be offered a rather difficult task, but first you should ask them to assess their own chances of accomplishing it. You can use a scale, for example, from 0 (I cannot manage at all) to 10 (I can manage brilliantly). Another way to detect unconscious incompetence may be a presentation when participants talk about situations taken from their own experience, in which they believe they acted correctly but did not achieve the desired result. Analysis of the factors, which prevented the achievement of the desired, will highlight the abilities they lacked. Next, students should discuss their emotional state, experiences, attitudes to the situation; and all that leads them to a conclusion that performing any task requires a certain competence. The next step is to build an algorithm for completing the task and explaining the rules of its implementation, forming a "conscious competence" of the students. To form "unconscious competence", we train the necessary skills and abilities in a certain area. You should take into account that the awareness of 
oneself's incompetence can frustrate people (Hayes, 1984; Sweeny, 2012), so it is important to monitor this process and to prevent frustration as soon as it arises. The transition from incompetence to competence is often associated with negative emotions, especially in adults who already have some life experience and often get used to feeling able to cope with various tasks. In order to acquire new knowledge and skills (or develop the existing ones), they must leave the comfort zone and enter the zone of discomfort. The comfort zone is a sociopsychological space in which a person clearly understands what is happening, feels confident and protected. In the area of discomfort, the person lacks knowledge and awareness, which causes anxiety, uncertainty, feeling insecure. The discomfort stimulates the search for information, creation of new behavioural patterns, formation of new skills. The trainer must remember to maintain a balance between psychological comfort and discomfort to prevent entering the zone of excessive uncertainty ("panic zone"). Excessive uncertainty causes fear and high anxiety, encouraging escape, self-defense and blocking of the ability to learn (Kurtikova, Lavrova \& Lee, 2005, p.17). This requires the trainer to be willing to work with the participants' negative emotions, so they could help to understand such reactions and their causes (Dirkx, 2008), to create a friendly atmosphere, and to encourage the transition to the next stages. Therefore, such a training design should include emotion-control strategy (Bell \& Kozlowski, 2008). Within one training, the formation of conscious competence should be considered the main aim. Because the formation of unconscious competence requires a considerable experience, the time constraints of the training usually do not allow to achieve such a result.

If we decide to divide the training on the basis of the external design type, we can distinguish two options: the design scenario may consist either of a set of topics represented by the sum of exercises, or form a coherent story.

Training design in the form of a "sum of exercises" (a consistent set of topics and exercises) is the most common option for designing a training program, when the trainer chooses one of the above described strategies and develops a program according to a specific topic or solution. The content of the exercises is usually unrelated. The design of the training in the form of a coherent story means that all the training material is a meaningful monolith, telling a certain real or fantasy story. An example of such an approach is a conflict resolution workshop developed by Canadian trainers Elaine Bushnik and Robert Birt (Canadian Institute for Conflict resolution, 2000, June). They invented a story about Crocodile City. The city is located on a river populated with crocodiles. Among the people living in the city, some misunderstandings arise, and listeners are asked to resolve them. During the training week, the stories of the inhabitants of this imaginary world unfold, and students become immersed in their problems, overcoming of which helps them to acquire the skills and abilities of conciliators. Coaches also can create their own imaginary worlds, cities, life stories, which can make the artistic background of the training, not only helping to make the presentation of the material coherent and logically appropriate, but also adding into the training process some elements of play, 
fiction, decorating the whole work. Such training becomes better remembered by students.

There is one more way to design training, with the participants maximally involved in its creation. The above described "connected story" version is the result of the coaches' creativity, and the seminar participants get a ready-made situation and make the exercises suggested by the coaches, performing the roles and images the coach (or someone else) invented. For enhancing the students' activity and adjustement to the problem raised at the seminar, you can involve the participants in creating the outline of the training by themselves. Here we will describe an example of such an exercise, which will be tentatively called "Creating a map of the world".

The work requires the following additional materials: multi-coloured markers (the more colours, the better) and several sheets of paper for a board (A-1 format). Divide the group into 5 small groups and give each of them a task to think on. In turn, they have to put their marks on the paper to form a map of the world. The first group should draw water and land (continents, islands, rivers, lakes, oceans). In this figure, the participants of the second group should specify the landscape: mountains, forests, glaciers, fertile lands, deserts, and so on. The task of the third group is to settle animals (these can be either existing species or fictional creatures). The fourth group should complete the new world with mineral resources (which also may be real or fictional). Finally, the participants of the fifth group should populate the world with inhabitants: mark the settlements and indicate the population.

When the "world map" is ready, the trainer divides the seminar participants into small groups, the number of which should fit the demands of the next work, and accordingly cuts the "world map" into the same number of parts. Depending on the purpose of further work, the map can be divided into equal parts or assume arbitrary proportions. Each small group gets its own "territory" with certain features. Now, each small group has to form a state on this territory (invent its name, think about what political and economic system it should have, and what beliefs, worldview, philosophy, culture, education, etc., its citizens have). On this background you can further build the whole training. For example, if you are making a training for trainers who already have professional experience, the next exercise may be to create an agency that offers coaching services in their country, to develop and demonstrate advertising for their agency. After that, you can show students some new techniques, share experiences and exercises, move on to developing training scenarios, and so on.

The creativity of the trainer in settling the story that can be used as "background" seems boundless: it is possible to create a galaxy, an alien planet, a city, a mechanism or organism with its own subsystems and features. According to the aim of the training and to the problem to be solved, it is possible to set a new story each time, and even more effective if it will be created by students: if people have created the world by themselves, they feel more comfortable within. Such a training structure makes the participants ready for active 
work, allows them to remove barriers, motivates towards unusual approaches and creativity, allows getting into a problem easily, etc. Observing the students' reactions allows us to say that the training story is more comfortable for the younger participants, and also for people with a well-developed imagination and rather artistic perception of the world. Middle-aged and late adults, and especially those who are prone to an algorithmic approach to acquiring knowledge, feel better in the "sum of exercises" type of training. The types of design selected by external organisation are close to the strategies of exploratory learning and guided exploration (Bell \& Kozlowski, 2008). A coherent story encourages an exploratory learning approach, and the sum of the exercises provides clearer instructions. However, in the sum of the exercises, the exploratory learning (although more fragmented) can be applied, and the coherent story can be remembered by the participants better as a structured and systematic whole.

\section{CONCLUSIONS}

In conclusion, we have to mention that in the process of developing training for adults, one should take into account the specifics of adult learning. In particular, such features as a conscious attitude to the learning process and its outcome, thus increased motivation, and also need for independence, life experience, need for practical training and so on. Active methods of adult education have proven their effectiveness and are widely used in training in various fields. As mentioned above, for effective training it is important to have not only a proper choice of the tasks and techniques, but also the internal and external logic of the training design in general, and its individual elements. We propose classification of the design of group training depending on the internal logic of the teaching material or on the external organisation of the training. The logic of the material presentation usually requires a certain form: from logical types of inferences (deductive, inductive and by analogy) to certain popular approaches to learning (organisation of information assimilation, Benjamin Bloom's taxonomy, competencies formation). You can also design the training in different ways: collect together separate exercises or create a coherent story. According to the aformentioned forms of organisation, it is possible to build both training as a whole, and its separate parts or thematic blocks and exercises. The training as a form of learning is attractive for both participants and trainers, probably because it provides a huge space for creativity not only in content but also in the forms of training organisation.

\section{RESEARCH PROSPECTS}

Prospects for further research in this area may be experimental studies of training programme effectiveness, built on the basis of different approaches to training design. In particular, it is important to study how the type of training 
design correlates with its effectiveness in groups of participants with certain characteristics: age, social status, intellectual level, certain features of temperament and character, personality traits, etc. It would also be interesting to explore the psychological characteristics of coaches who prefer a certain form of training.

\section{REFERENCES}

[1] Anderson, L., \& Krathwohl, D. R. (2001). A Taxonomy for Learning, Teaching and Assessing: A revision of Bloom's Taxonomy of Educational Objectives. New York: Longman.

[2] Annis, L. F. (1983). The processes and effects of peer tutoring. Human Learning, 2, 39-47.

[3] Anishchenko, О. (2015). Методика організації і проведення тренінгів 3 розвитку особистісних і професійних якостей дорослих. [Methods of organizing and realization of training on the development of personal and professional qualities of adults]. Adult Education: Theory, Experience, Prospects: collection of scientific papers, 2(11), 14-20.

[4] Aronson, E., Blaney, N., Stephan, C., Sikes, J., \& Snapp, M. (1978). The Jigsaw Classroom. Beverly Hills, CA: Sage Publication Company.

[5] Bavina, P. A. (2006). Тренинговые технологии в формировании коммуникативной компетентности будущих менеджеров [Training technologies in the formation of the communicative competence of future managers]. St. Petersburg: PhD thesis abstract., 1-26.

[6] Bell, B. S., \& Kozlowski, S. W. J. (2008). Active learning: Effects of core training design elements on self-regulatory processes, learning, and adaptability. Journal of Applied Psychology, 93(2), 296-316.

[7] Benware, C. A., \& Deci, E. L. (1984). Quality of learning with an active versus passive motivational set. American Educational Research Journal, 21, 755-765.

[8] Bloom, B. S. (1984). Taxonomy of educational objectives: The classification of educational goals. New York: Longman.

[9] Broadwell, M.M. (1969). Teaching for learning (XVI). The Gospel Guardian, 20 (41), 1-3.

[10] Cheng, S., Sun, Y. et al. (2017). A comprehensive survey of brainstorm optimization algorithms. IEEE Congress on Evolutionary Computation (CEC), San Sebastian, 1637-1644.

[11] Dirkx, J. M. (2008). The meaning and role of emotions in adult learning. New Directions for Adult and Continuing Education, 120, 7-18.

[12] Duran, D. (2016). Learning-by-teaching. Evidence and implications as a pedagogical mechanism. Innovations in Education and Teaching International, 54(5), 476-484.

[13] Feinstein, L., \& Hammond, C. (2004). The contribution of adult learning to health and social capital. Oxford Review of Education, 30(2), 199-221.

[14] Fiorella, L., \& Mayer, R. (2013). The relative benefits of learning-by-teaching expectancy. Contemporary Educational Psychology, 38, 281-288.

[15] Geller, E.S. (2002). The challenge of increasing proenvironmental behavior. In: R. B. Betchel, A. Churchman (Eds.), Handbook of Environmental Psychology (pp. 525-540). New York: y John Wiley \& Sons, Inc.

[16] Hayes, J. (1984). The Politically Competent Manager. Journal of General Management, 10(1), 24-33.

[17] Kovaleva, Т. (2005). Решение коммуникативно-познавательных задач при обучении профессионально-ориентрованному иноязычному информативному чтению будущих учителей [The solution of communicative and cognitive tasks in the teaching professionally-oriented foreign language informative reading to future teachers]. Ekaterinburg: PhD thesis abstract. Retrieved from: http://elar.uspu.ru/bitstream/uspu/93/1/aref00107. pdf

[18] Knowles, M. S., Holton, E. F. \& Swanson, R. A. (2005). The adult learner: the definitive classic in adult education and human resource development (6th ed.). Burlington: Elsevier.

[19] Kondratenko, V., Donskoy, D. (1997). Общзая психотерапия. [General psychotherapy]. Minsk: High School. 
[20] Kurtikova, I., Lavrova, K., Lee, V. (2005). Тренинг: руководство кдействию. Теория и практика. [Training: the guide to action. Theory and practice.]. Moscow: AIDS Foundation East-West.

[21] Lukyanova, L. (2013). Тренінгові технології в освіті дорослих [Training technologies in education for adults]. In: L. Lukyanova, O. Anishchenko, L. Sigaeva, S. Zinchenko, O. Banit \& N. Doroshenko, Modern technologies of adult education (pp. 6-39). Kirovograd: Imex-LTD.

[22] European Association for the Education of Adults. (2019). Manifesto for Adult Learning in the 21st Century: The Power and Joy of Learning. Retrieved from https://eaea.org/wpcontent/ uploads/2019/04/eaea_manifesto_final_web_version_290319.pdf

[23] Miroshnyk, S. (2012). Навчальний тренінг як оптимальна форма організації навчання педагогічних працівників в умовах післядипломної педагогічної освіти [Educational training as the best form of organization of teachers' learning in terms of in-service pedagogical education]. Electonic Scientific Publication "Public Education". Retrieved from: https://repository.kristti.com.ua/handle/eiraise/269

[24] Mount, D., \& Mazerolle, L. (2020). Investigative interviewing skills in policing: Examining the transfer of training into workplace practices. Policing: An International Journal. Retrieved from: https://www.emerald.com/insight/publication/issn/1363-951X

[25] O'Connell S., Medeni A. (2014). A Trainer's Guide: How to Design and Deliver Training with impact. National Democratic Institute. Retrieved from: https://www.ndi.org/sites/default/ files/How\%20to\%20Train\%20Manual_EN.pdf

[26] Salas, E., \& Cannon-Bowers, J. A. (2001). The Science of Training: A Decade of Progress. Annual Review of Psychology, 52(1), 471-499.

[27] Slavin, R. E. (1980). Cooperative learning. Review of Educational Research, 50(2), 315-342.

[28] Sweeny, J. (2012). Emotional Editing. 20 Perspectives: Perspectives: Teaching Legal Research \& Writing, 109, 1-4. Retrieved from: https://ssrn.com/abstract=2445519

[29] Vovk, M. Khodakivska, S. (2019). Технології навчання дорослих в умовах формальної і неформальної освіти [Adult learning technologies in the conditions of formal and non-formal education]. Adult Education: Theory, Experience, Prospects, 2 (16), 39-48.

[30] Zajonc, R. B. (1966). Social psychology: An experimental approach. Belmont, CA: Wadsworth. 